\title{
Spleen Focus-Forming Virus
}

National Cancer Institute

\section{Source}

National Cancer Institute. Spleen Focus-Forming Virus. NCI Thesaurus. Code C14276.

Defective virus found in certain strains of Friend virus, detected by its ability to form foci in spleens of mice and believed to be responsible in those strains for the production of a leukemia associated with polycythaemia rather than anemia. (DictionaryBarn.com) 